\title{
Leprosy in Uganda.
}

R. G. Cochrane.

U GANDA with a territory about equal in size to Great Britain and Ireland and with approximately one-eighth of the population, has an estimated incidence of leprosy of 20,000. The leprosy situation here is entirely different from that of the Sudan. Firstly, the disease is widespread over the whole territory, secondly, the people are more sophisticated and less-amenable to strict discipline, and lastly there are so many lepers that it would be a physical impossibility to confine to one area all known cases. While any anti-leprosy scheme must be as complete as possible, the amount of money ear marked for leprosy should bear some reasonable proportion in comparison with the general medical budget. This is especially the case where the financial resources are limited. Few colonies can spend as much as 25 per cent. of their total medical allotment on leprosy as is done in some countries.

For administrative purposes Uganda is divided into four provinces, viz., Northern, Eastern, Buganda and Western, and the leprosy situation will be considered in each of these provinces.

\section{Northern Province.}

The exact situation in this province is unknown. At Arua, on the Sudan border, there are a few cases of leprosy being treated at the local Government hospital. There are five leprosy camps throughout this province, accommodating some seventy-six patients. Little can be suggested regarding measures to be taken until further information regarding the type and incidence of the disease is available. As the Arua district of the Northern Province is within a sleeping sickness area, and as periodical inspections are carried out, much information could be gathered regarding the disease if medical officers, when on the look-out for sleeping sickness, would also keep a watch for cases of leprosy. Leprosy is a disease which lends itself to a rapid survey, for not only can the majority of cases be very easily discovered from an examination of a group of natives, but in many instances the infective and non-infective cases can be readily separated.

Although the incidence of leprosy in the N. Province is surmised to be high, it has been considered that venereal disease is the more pressing problem. While not wishing to minimise the danger and importance of venereal diseases in a 
community, yet leprosy is so slow in its spread that its presence is not so likely to receive official notice. However, as venereal diseases in general, and syphilis in particular, are one of the chief predisposing causes of leprosy, any measure which aims at their eradication will indirectly benefit the leprosy campaign. It was suggested, therefore, that the venereal diseases campaign should be rigorously pursued, but at the same time a preliminary survey of the number of cases and the type of leprosy should be undertaken, and until more accurate knowledge of the situation is obtained all that can be done is to encourage known sufferers to come to dispensaries for treatment.

\section{Eastern Province.}

This is one of the most heavily infected areas in the whole of Uganda, and has the unenviable reputation of being one of the worst areas for leprosy in Central Africa. There is a good deal of evidence suggesting that leprosy has been spreading in the Eastern Province during the last twentyfive years. There are two possible causes for this.

(1) The people have no fear of the disease and the tribes, especially the Teso, are ignorant and dirty, and do not understand the elements of cleanlines .

(2) During the past quarter of a century roads have opened up the country to such an extent that every part of the country is easy of access.

Thus a disease such as leprosy may have been introduced into areas which were previously cut off from close communication.

For the purposes of this report the Eastern Province can be considered in three areas : (1) The district around and in the vicinity of Lira. (2) The district around Ngora. (3) The district around Mbale.

(1) Lira District.

It appears that there are two heavily infected foci in this district.

(a) Kuman county.

(b) Kwania county.

(a) The former area comprise the region around Lake $\mathrm{Kioga}$, and is rather inaccessible. There is a government dispensary contemplated at Kabermaido, and this would make a convenient place for an out-patient centre, and later, if necessary, a colony. It has been suggested that until some general plan is organised for the whole of the Eastern Province an outpatient centre hould be organised at Kabermaido 
with a reliable native medical officer in charge. All patients coming to this dispensary should be treated and the danger to others of cases in the contagious stage of the disease impressed upon the people and particularly on the chiefs. In such a highly infected focus a leprosy colony might be considered at a later date.

The focus in the Kwania country is not so inaccessible as that of Kuman. There is a camp at Aduku which is accessible by the medical officer situated at Lira. In the camp there are about 100 cases segregated. It should be possible to meet the needs of this district by developing this camp. It has been estimated that there are some 2,000 sufferers in the district. From the brief survey it is calculated that for this area the number of infective cases per 100 is about eleven ; this would mean that if the accommodation of this camp were doubled it would meet the need of the district fairly satisfactorily as far as the infective cases were concerned. At Soroti the out-patient centre which was started by Dr. Wiggins, has been taken over by Government. With the development of the camp at Aduku and extension of the work for early cases at Lira and Soroti the situation for the Kuman country should be fairly well met.

\section{Ngora District.}

Dr. Wiggins of Ngora has developed an extensive antileprosy work in this district. When the Secretary visited Uganda there were four out-patient centres and the infective cases hospital at Kapiri was in the process of construction while the children's hospital at Kumi was occupied. As a result of the withdrawing of a mild measure of compulsion the attendance at the various out-patients centres fell off very markedly. At one time the total attendance was somewhere between two and three thousand. The Secretary in his report stated that at present the most important step was to organise a system whereby infectious cases and children are isolated, and until a scheme had been formed to deal with cases in every stage of the disease, the question of trying compulsorily to enforce treatment on all sufferers from leprosy would only confuse the issue. Further, the present available medical staff was unable to cope with the situation arising out of compulsory treatment.

Since the Secretary's visit the infectious diseases hospital at Kumi has been opened and filled and the total accommodation is 150. Since the end of April (1930) children have had to be turned away and the chiefs informed that no more could be taken in. The first batch to be discharged 
was sent out last January, and an equal number of new ones admitted. A trained nurse is now in charge of the children at this hospital. The hospital for infectious cases at Kapiri was opened last November, and there are already 120 patients in residence.

\section{Mbale District.}

In this district, the Secretary toured for three days and visited some twelve villages, and during this time he came across over 700 cases of leprosy. It is estimated that in this one area there are probably at least 3,000 sufferers, and that the percentage of highly infective cases was about 10 per cent., and that of mildly infective cases was as high as 16 per cent. A large number of apparently healthy adults were seen who had one or two patches of hypopigmentation which had been present for years. It was felt that these cases were individuals who had acquired a mild infection and owing to their high resistance, the disease had not advanced and had become arrested, the few hypopigmented areas remaining being permanent. The question of the presence of the so-called " abortive case" opens up an interesting point in connection with field investigation. In the Mbale district it is distressing to realise that except for a few cases treated at local dispensaries very little is being done for the rest.

\section{Western Province.}

There are undoubtedly a large number of cases in the Western Province, and the Kigezi district represents a large foci of the disease. The fact that impressed the Secretary on his tour in this area was the large number of highly infective cases seen, whereas the percentage of this type of leprosy in the Eastern Province was about ten; in the Western Province the percentage was as high as 50 per cent. The difference in the relative incidence of infective and non-infective cases in various areas needs further study, and systematic field work linked up with a well organised leprosy hospital, I feel sure, would reveal epidemiological factors of great importance.

Drs. Sharpe and Smith are organising a leprosy settlement on an island in their district and as it is hoped to publish an article by Dr. Smith shortly, this aspect of the work will not be touched.

It is an interesting and arresting fact that territories adjacent to the Belgian Congo have a very high incidence of leprosy. Both in Belgian and British Ruanda it is said that 
Sketch Map of Uganda Showing Main 'Treatment Centres

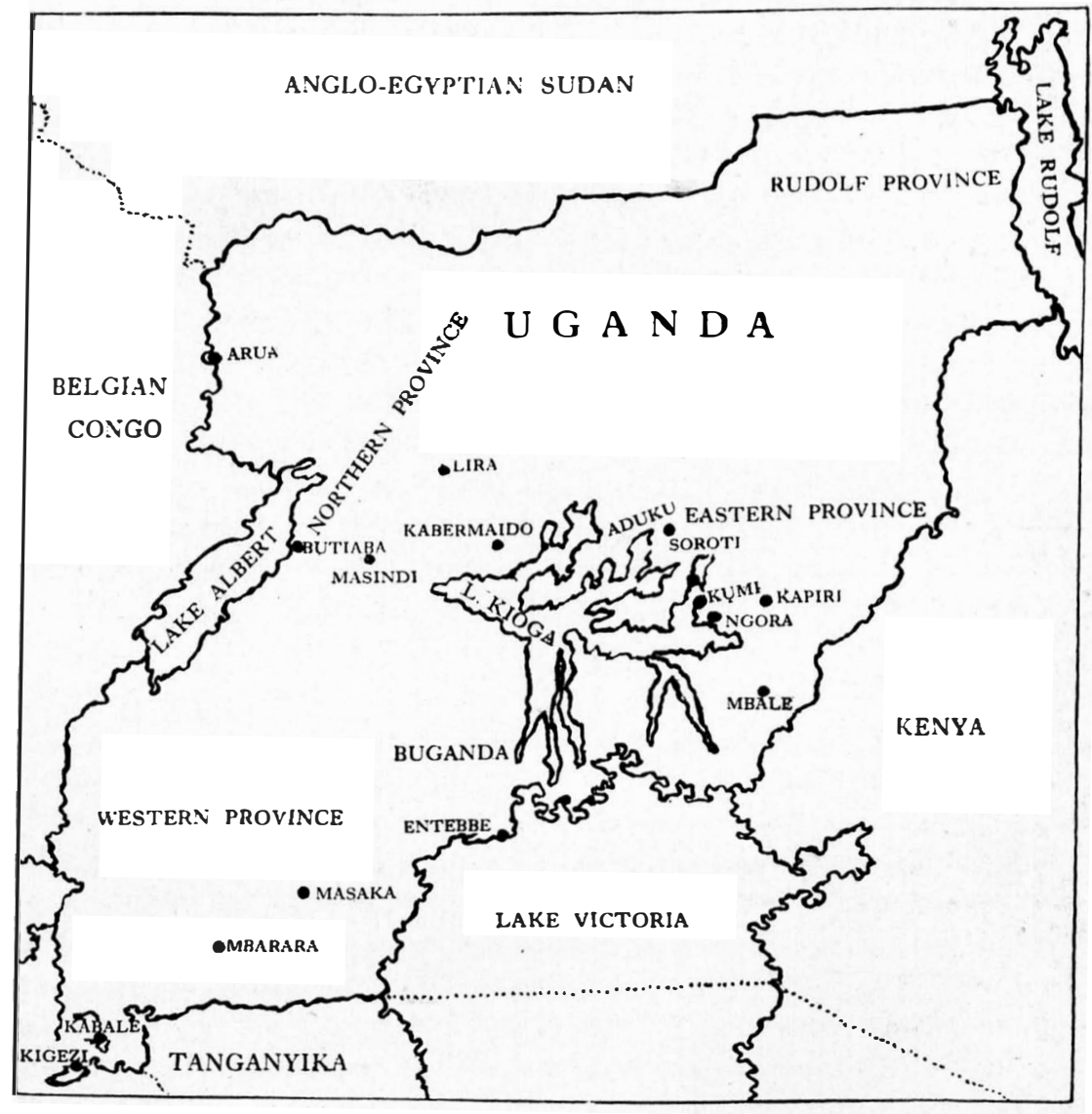




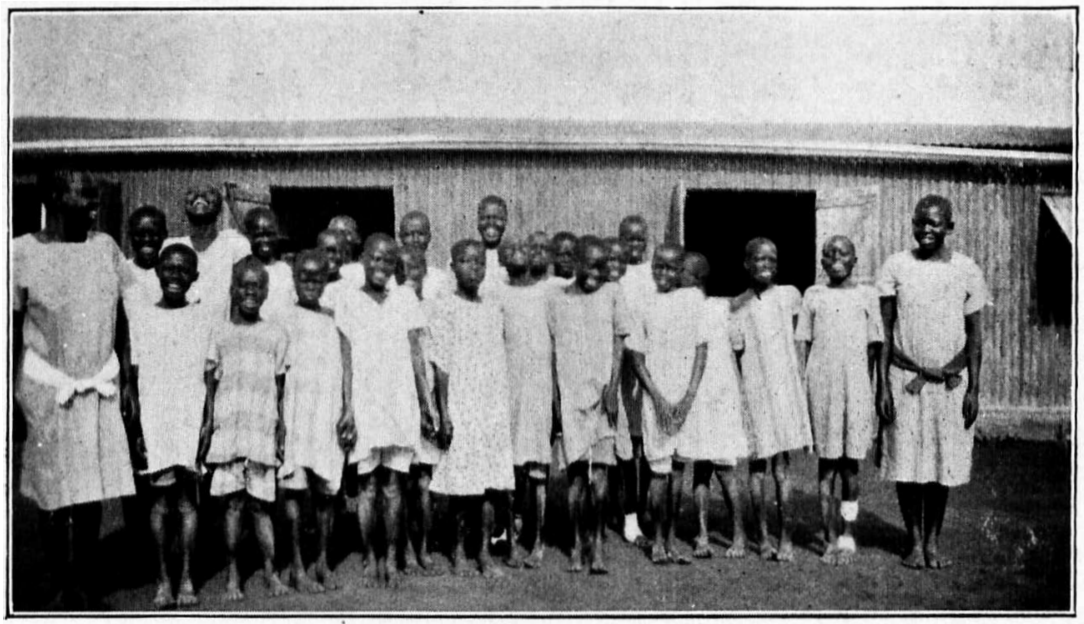

A Group of Happy leper Girls at Kumi, Uganda.

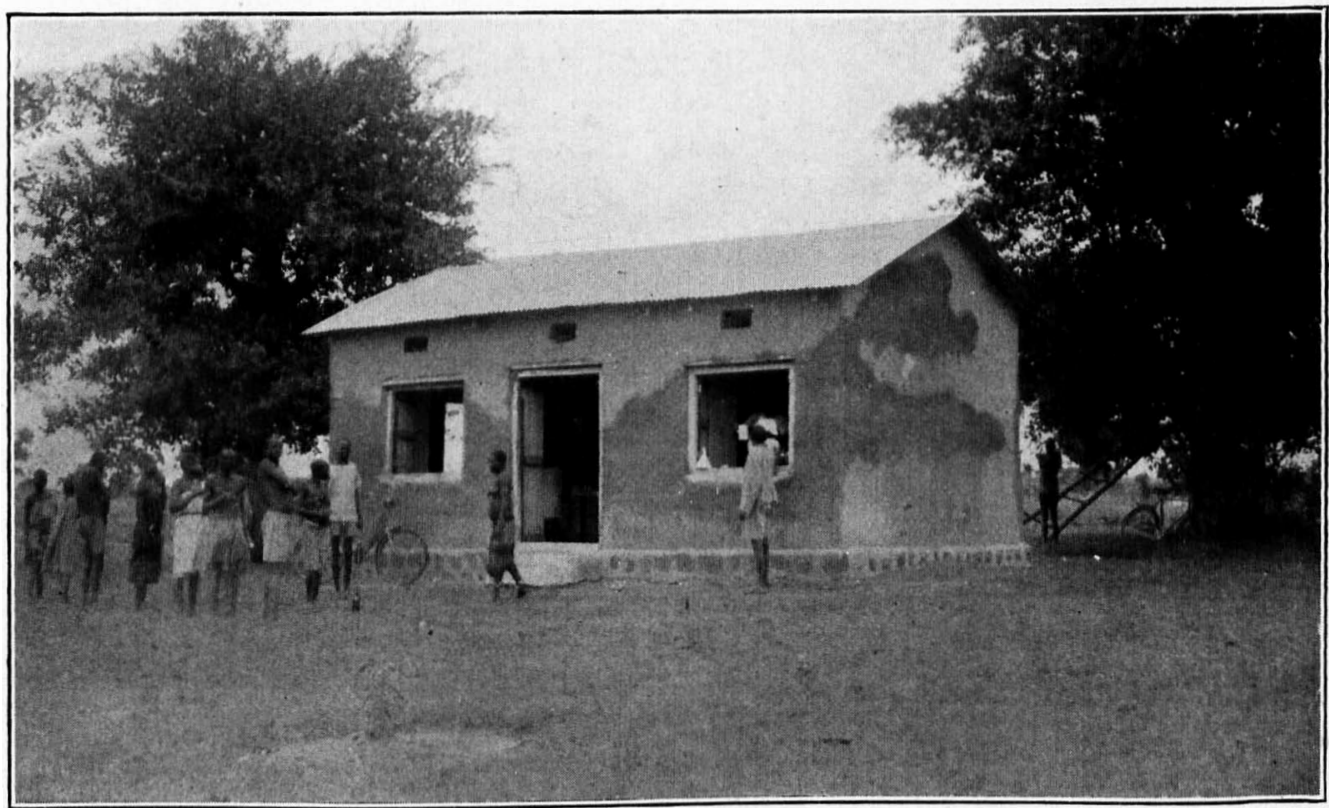

Leprosy Treatment Station, near Ngora, Uganda. 
the number of cases of leprosy and the incidence of the disease is even higher than in the Kigezi district. Certain parts of the Belgian Congo seem to be highly endemic areas from where leprosy has spread to adjacent territories.

\section{Buganda Province.}

This province, consisting as it does, of the Kingdom of Buganda is more developed and the people are more highly civilised than any other part of Uganda. As a result it is not surprising to find that the people have a great dread of the disease. While it is said that there is little leprosy in Buganda yet where there is such fear, it is quite possible that a great deal is hidden, especially in the earlier stages. From statements by officials it appears that the incidence of leprosy is highest in those parts of the province which border the Eastern Provinces. This is to be expected, considering the high incidence in the latter area.

The Government is contemplating an extensive survey of leprosy throughout the territory which would include Buganda.

It will be seen from the foregoing information that the problem in Uganda is one of immense magnitude, and at present only the fringe is being touched. So vast is the problem and so inadequate the resources that the Secretary in his report stated that at present it was a physical impossibility to treat all sufferers from leprosy in Uganda, and therefore, the first aim should be to concentrate on the treatment of early cases among children, and isolate, where possible, infective cases. The Secretary in his report suggested the appointment of a full time leprosy officer, and the development of a model leprosy settlement in the Mbale district. If this were done, and a system organised which embraced dispensary treatment, field investigation and propaganda throughout the territory, this combined with the work the Mission to Lepers is doing in the Eastern and Western Provinces, should go a long way towards the control of the disease. Unfortunately financial resources are so meagre that at present there is little prospect of any such complete system being organised. 